\title{
Pulmonary Hypertension: Endothelial Cell Function
}

\author{
Rajamma Mathew \\ Dept of Pediatrics, Maria Fareri Children's Hospital at Westchester Medical Center, \\ New York Medical College, Dept. of Physiology, New York Medical College, Valhalla, NY,
}

USA

\section{Introduction}

Pulmonary hypertension (PH) is a devastating sequel of a number of diverse systemic diseases including cardiopulmonary, autoimmune, inflammatory and myeloproliferative diseases, drug toxicity, acquired immunodeficiency syndrome, portal hypertension, sickle cell disease and thalassemia etc. Despite major advances in the field, precise mechanism/s of $\mathrm{PH}$ is not yet fully understood. In experimental models, endothelial dysfunction is reported to occur before the onset of $\mathrm{PH}$. Therefore, it is not surprising that the clinical diagnosis is often made late during the course of the disease. The major features of $\mathrm{PH}$ are impaired vascular relaxation, smooth muscle cell hypertrophy and proliferation, narrowing of the lumen, elevated pulmonary artery pressure and right ventricular hypertrophy. As the disease progresses, neointima formation takes place leading to further narrowing of the lumen, worsening of the disease, right heart failure and death.

Endothelial cells (EC) maintain a balance between vasoconstriction and vasodilatation, and between cell proliferation and apoptosis. In addition, they provide barrier function, balance pro- and anticoagulation factors of the vessel wall, and participate in immune function. Plasmalemmal membrane of the EC have specialized microdomains such as caveolae, rich in cholesterol and sphingolipids that serve as a platform for a numerous signaling molecules and compartmentalize them for optimum function. Caveolin-1, a major protein constituent of caveolae maintains the shape of caveolae and interacts with numerous signaling molecules that reside in or recruited to caveolae, and stabilizes them and keeps these molecules in an inhibitory conformation. A large number of signaling pathways implicated in $\mathrm{PH}$ have been shown to interact with endothelial caveolin-1. Therefore, endothelial dysfunction including the loss of functional endothelial caveolin-1 induced by injury such as inflammation, toxicity, increased shear stress and hypoxia may be the initiating factor in the pathogenesis of $\mathrm{PH}$ and also contributing to the progression of the disease.

\section{Pulmonary Hypertension}

$\mathrm{PH}$ is a rare but a devastating disease with high mortality and morbidity rate. A large number of unrelated diseases are known to lead to PH. The current W.H.O. clinical classification of $\mathrm{PH}$ includes 5 groups: $\mathrm{Gr}$ I: Pulmonary arterial hypertension (PAH): This group comprises of idiopathic and heritable PAH, PAH secondary to drug toxicity and 
associated with congenital heart defects, connective tissue diseases, portal hypertension, infection, chronic hemolytic anemia, and persistent pulmonary hypertension of the newborn. Recently, pulmonary veno-occlusive disease and pulmonary capillary hemangiomatosis have been added to this group as a subcategory. Gr II: PH due to left heart diseases, Gr III: PH due to lung diseases and hypoxia, Gr IV: Chronic thromboembolic PH, and $\mathrm{Gr} V$ : PH secondary to other systemic diseases such as sarcoidosis, myeloproliferative diseases, metabolic disorders and chronic renal failure on dialysis etc. (Simonneau 2004, Hoeper 2009). Regardless of the underlying disease; the major features of PH are endothelial dysfunction, impaired vascular relaxation, smooth muscle cell proliferation and impaired apoptosis, neointima formation, narrowing of the lumen, elevated pulmonary artery pressure and right ventricular hypertrophy, subsequently leading to right heart failure and death. Early changes that occur in the vasculature are not clinically apparent. The patients usually present with vague symptoms, therefore it is not surprising that the diagnosis is often made late. By the time the diagnosis is made, extensive vascular changes have already taken place, which makes the treatment a formidable challenge.

Although major advances have been made, the precise mechanism/s leading to $\mathrm{PH}$ is not yet fully elucidated. Multiple signaling pathways have been implicated in the pathogenesis of $\mathrm{PH}$. Loss of nitric oxide (NO), prostacyclin $\left(\mathrm{PGI}_{2}\right)$ and resulting impaired vascular relaxation is the hallmark of $\mathrm{PH}$. Recent studies have revealed that certain genetic defects in humans increase the likelihood of developing PAH. Several members of transforming growth factor (TGF) $\beta$ superfamily have been implicated in the pathogenesis of PAH; the most notable example being heterozygous germline mutations in bone morphogenic protein receptor type II (BMPRII). This mutation has been noted in approximately $70 \%$ of heritable $\mathrm{PAH}$ and $26 \%$ of idiopathic PAH. Importantly, only $20 \%$ of people with this mutation develop PAH. It has recently been shown that inflammation and serotonin increase susceptibility to develop PH in BMPRII+/- mice (Thomson 2000, Machado 2006, Long 2006, Song 2008, Mathew 2011b). Altered metabolism of estrogen resulting in low production of 2 methylestradiol is also thought to be a "second hit" for the development of PAH in females with BMPRII mutation (Austin 2009). Thus, environmental, metabolic and/or other genetic factors act as a "second hit" in the development of PAH in patients with BMPRII mutations.

Inflammation plays a significant role in the pathogenesis of clinical and experimental $\mathrm{PH}$. $\mathrm{PH}$ has been reported in patients suffering from systemic inflammatory, autoimmune diseases and human immunodeficiency virus infection (Lespirit 1998, Dorfmüller 2003, Mathew 2010). In patients with idiopathic PAH, increased plasma levels of proinflammatory cytokines and chemokines such as interleukin (IL)-1, IL-6, fractalkine and monocyte chemoattractant protein-1 (MCP-1, currently known as CCL2) have been documented. Perivascular inflammatory cells, chiefly macrophages and monocytes, and regulated upon activation normal T-cell expressed and secreted (RANTES) have also been reported in the lungs of these patients [Tuder 1994, Humbert 1995, Dorfmüller 2002, Balabanian 2002, Itoh 2006, Sanchez 2007, Mathew 2010). In the monocrotaline (MCT) model, early and progressive upregulation of IL-6 mRNA with increased IL-6 bioactivity, progressive loss of endothelial caveolin-1 coupled with activation (tyrosine phosphorylation, PY) of signal transducer and the activator of transcription (STAT) 3 have been shown to occur before the onset of PH; and the rescue of endothelial caveolin-1 inhibits PY-STAT3 activation and attenuates PH (Mathew 2007, Huang 2008). These observations not only underscore a role for inflammation in the pathogenesis of $\mathrm{PH}$ but also show the importance of endothelial cell membrane integrity in vascular health. 
BMPRII is predominantly expressed in endothelial cells (EC). A part of BMPRII has been shown to colocalize with caveolin-1 in caveolar microdomain and also in golgi bodies. BMPRII signaling is essential for BMP-mediated regulation of vascular smooth muscle cell (SMC) growth and differentiation, and it also protects EC from apoptosis (Yu 2008, TeichertKuliszewska 2006). In some cell systems, persistent activation of PY-STAT3 leads to a reduction in the BMPRII protein expression, and BMP2 induces apoptosis by inhibiting PYSTAT3 activation and by down-regulating $\mathrm{Bcl}-\mathrm{xL}$, a downstream mediator of PY-STAT3 (Brock 2009, Kawamura 2000). In addition, the loss of BMPRII in in-vivo and in-vitro studies has been shown to increase the production of cytokines such as IL-6, MCP-1 and TGF $\beta$; and exogenous BMP ligand decreases these cytokines. Interestingly, reduction in the expression of BMPRII has been reported in patients with idiopathic PAH without BMPRII mutation and to a lesser extent in patients with secondary PH (Atkinson 2002, Mathew 2010). Furthermore, both MCT and hypoxia models of $\mathrm{PH}$ exhibit reduction in the expression of BMPRII (Murakami 2010, Reynolds 2009). Since there is a significant interaction and crosstalk between the BMP system and IL-6/STAT3 pathway, a reduction in the expression of BMPRII may exacerbate inflammatory response in PH.

\section{Endothelial cell function}

Endothelium, a monolayer lining the cardiovascular system, is a critical interface between circulating blood on one side, and tissues and organs on the other. EC form a nonthrombogenic and a selective barrier to circulating macromolecules and other elements. Vascular EC subjected to blood flow-induced shear stress transform mechanical stimuli into biological signaling. EC are a group of heterogeneous cells adapted to function for the underlying organs. They have numerous metabolic functions. Depending on the stimuli they are capable of secreting several transducing molecules for participation in vascular tone and structure, inflammation, thrombosis, barrier function, cell proliferation and apoptosis. The dominance of these various factors, determines whether the effect would be cytoprotective or cytotoxic. EC have specialized microdomains on the plasmalemmal membrane. Caveolae, a subset of these specialized microdomains are omega shaped invaginations (50-100 nm) found on a variety of cells including EC, SMC and epithelial cells. Caveolae serve as a platform and compartmentalize a number of signaling molecules that reside in or are recruited to caveolae. Caveolae are also involved in transcytosis, endocytosis and potocytosis. Three isoforms of caveolin proteins have been identified. Caveolin-1 (22kD) is the major scaffolding protein that supports and maintains the structure of caveolae. It interacts with numerous transducing molecules that reside in or are recruited to caveolae, and it regulates cell proliferation, differentiation and apoptosis via a number of diverse signaling pathways. Caveolin-2 requires caveolin- 1 for its membrane localization and functions as an anti-proliferative molecule. However, unlike caveolin-1, caveolin-2 has no effect on vascular tone. Caveolin-3 is a muscle specific protein found predominantly in cardiac and skeletal muscle (Razani 2002, Mathew 2011b).

Caveolin-1 interacts, regulates and stabilizes several proteins including Src family of kinases, G-proteins (a subunits), G protein-coupled receptors, H-Ras, PKC, eNOS, integrins and growth factor receptors such as VEGF-R, EGF-R. Caveolin-1 exerts negative regulation of the target protein within caveolae, through caveolin-1-scaffolding domain (CSD, residue 82-101). Major ion channels such as $\mathrm{Ca}^{2+}$-dependent potassium channels and voltagedependent $\mathrm{K}^{+}$channels (Kv1.5), and a number of molecules responsible for $\mathrm{Ca}^{2+}$ handling such as inositol triphosphate receptor $\left(\mathrm{IP}_{3} \mathrm{R}\right)$, heterodimeric GTP binding protein, $\mathrm{Ca}^{2+}$ 
ATPase and several transient receptor potential channels localize in caveolae, and interact with caveolin-1. Production of vasodilators such as nitric oxide (NO), prostacyclin $\left(\mathrm{PGI}_{2}\right)$ and endothelium-derived hyperpolarizing factor [EDHF] within caveolae are dependent on caveolin-1-mediated regulation of $\mathrm{Ca}^{2+}$ entry (Mathew 2011b).

EC have important cytoplasmic organelles such as Weibel Palade bodies, initially formed in trans-golgi network; as these organelles mature they become responsive to secretagogues such as thrombin and histamine. Weibel Palade bodies store a number of molecules that are necessary for hemostasis, inflammation, vascular proliferation and angiogenesis. These molecules including vWF, P-selectin, angiopoietin 2, ET-1 and endothelin converting enzyme, IL-8, calcitonin gene-related peptide and osteoprotegerin are readily available for the designated function (Metcalf 2008).

\subsection{Vasomotor tone}

\subsubsection{Endothelial nitric oxide synthase (eNOS)/cyclic guanosine monophosphate (cGMP) pathway}

eNOS/cGMP pathway plays a major role in vascular tone and structure. In addition to vasodilatory function, it inhibits cell proliferation, DNA synthesis, platelet aggregation, and it modulates inflammatory responses. eNOS is tightly regulated by a variety of intracellular processes, post-translational modification and protein-protein interaction with caveolin-1 and $\mathrm{Ca}^{2+} /$ calmodulin. For efficient synthesis, eNOS is associated with golgi bodies, and for optimum activation, eNOS is targeted to caveolae. An increase in intracellular $\mathrm{Ca}^{2+}$ induced by shear stress and varying oxygen tension activate eNOS (Sessa 1995, Shaul 1996). NO, a short lived free radical gas is synthesized by the catalytic activity of eNOS on L-arginine in the vascular EC. NO activates the enzyme, soluble guanylate cyclase (sGC) that converts guanosine triphosphate (GTP) to cGMP.

cGMP through its protein kinase (PKG) causes vascular relaxation, inhibits cell proliferation and inflammation. It is thought that the extracellular L-arginine and its transport through cationic amino acid transporter-1 (CAT-1), localized in the caveolae, are available for eNOS activity. L-arginine found in different intracellular compartments may not be readily available for eNOS activity. This dependence on extracellular L-arginine for NO production has been termed "L-arginine paradox" (McDonald 1997, Zharikov 1998). In addition to CAT-1, tetrahydrobiopterin (BH4) and sGC are compartmentalized in caveolae with eNOS for optimum activation. BH4 is an essential cofactor required for the activity of eNOS and is synthesized from GTP by a rate limiting enzyme, guanosine triphosphate cyclohydrolase 1 (GTPCH-1). Interestingly, GTPCH-1 also localizes in caveolar microdomain with caveolin-1 and eNOS. This spatial colocalization with eNOS may ensure NO synthesis (Peterson 2009). Caveolin-1 inhibits eNOS through protein-protein interaction, but it also facilitates the increase in intracellular $\mathrm{Ca}^{2+}$. HSP90 binds to eNOS away from caveolin-1 in $\mathrm{Ca}^{2+}$ calmodulin-depedent manner and reduces the inhibitory influence of caveolin-1 to increase eNOS activity. Thus, caveolin-1 and eNOS have a dynamic interrelationship (Gratton 2000, Mathew 2007).

\subsubsection{Prostacyclin $\left(\mathrm{PGI}_{2}\right)$ /cyclic adenosine monophosphate (cAMP) pathway}

$\mathrm{PGI}_{2}$, a potent vasodilator produced by EC is formed from arachidonic acid by the enzymatic activity of $\mathrm{PGI}_{2}$ synthase, catalyzed by cyclooxygenase 2 . $\mathrm{PGI}_{2}$ synthase belongs 
to a family of G-protein coupled receptors and it colocalizes with endothelial caveolin-1. $\mathrm{PGI}_{2}$ binds to the receptor resulting in the stimulation of adenylyl cyclase which catalyzes the conversion of ATP to second messenger cAMP. In vascular system, $\mathrm{PGI}_{2}$ via cAMP and cAMP-dependent protein kinase (PKA) promotes vascular relaxation, inhibits platelet aggregation, inflammation and cell proliferation. In addition, cAMP/PKA pathway activates NO production via phosphorylation of eNOS (Stitham 2011, Kawabe 2010, Zhang 2006). Unlike eNOS, $\mathrm{PGI}_{2}$ synthase remains enzymatically active even when bound to caveolin-1. Furthermore, eNOS, $\mathrm{PGI}_{2}$ synthase and vascular endothelial growth factor receptor (VEGFR) 2 colocalize with caveolin-1 suggesting a role for caveolin-1 in angiogenesis signaling pathways (Spisni 2001).

\subsubsection{Endothelium-derived hyperpolarizing factor (EDHF)}

An elevation of intracellular $\mathrm{Ca}^{2+}$ is essential for EDHF-mediated responses; and the family of transient receptor potential cation (TRPC) channels participates in $\mathrm{Ca}^{2+}$ entry. TRPC1 is associated with caveolae and a direct interaction with caveolin-1 is necessary for TRPC membrane localization, and $\mathrm{Ca}^{2+}$ influx. $\mathrm{Ca}^{2+}$ influx also occurs via TRPV4 channel that belongs to a subfamily of TRPC. TRPV4 channel is expressed in a variety of cells including EC, and is also linked to caveolin-1. Interestingly, arachidonic acid metabolites epoxyeicosatrienoic acids (5, 6-EET and 8, 9-EET) act as direct TRPV4 channel activators in EC. Furthermore, genetic deletion of caveolin-1 has been shown to abrogate EDHF-induced hyperpolarization by altering $\mathrm{Ca}^{2+}$ entry, thus highlighting the role of caveolin- 1 in EDHF regulation (Rath 2009, Vriens 2005, Saliez 2008).

\subsection{Barrier function}

Endothelial cytoskeleton maintains barrier integrity, and EC are linked with each other through tight junctions (TJ) and adherens junctions (AJ). EC control the passage of blood constituents to the underlying tissue. The solutes pass through transcellular or paracellular pathway. Transcellular permeability is regulated by signaling pathways responsible for endocytosis and vesicular trafficking. Paracellular permeability is the result of opening and closing of the endothelial cellular junction; it is governed by a complex arrangement of adhesion proteins and related cytoskeleton proteins organized in distinct structures such as TJ and AJ. Vascular endothelial (VE)-cadherin plays a critical role in integrating spatial signals into cell behavior. VE-cadherin interacts with $\beta$-catenin, p120 and plakoglobulin, and binds to a-catenin. Association of VE-cadherin with catenins is required for cellular control of endothelial permeability and junction stabilization. It is believed that the tyrosine phosphorylation of VE-cadherin and other components of AJ results in a weak junction and impaired barrier function (Dejana 2008, Mahta 2006). Furthermore, VE-cadherin is a link between AJ and TJ; it upregulates the gene encoding for the protein claudin-5, a TJ adhesive protein (Taddei 2008). RhoA is considered crucial for the endothelial contractile machinery. Basal activity of RhoA maintains EC junctions, but the induced activity mediates cell contraction, AJ destabilization, barrier disruption and increased permeability. Suppression of RhoA by the activation of p190RhoGAP (GTPase activating protein) reverses permeability. Interestingly, caveolin-1 deficiency impairs AJ integrity and reduces the expression of VE-cadherin and $\beta$-catenin. In caveolin- 1 deficient EC, increased activity of eNOS accompanied by reactive oxygen species (ROS) generation leads to nitration; the 
consequent inactivation of p190RhoGAP-A results in RhoA activation and increased permeability. Inhibition of RhoA or eNOS reduces hyper-permeability in caveolin-1/- mice (van Nieuw Amerongen 2007, Siddiqui 2011, Schubert 2002). It has also been shown that NO-mediated s-nitrosylation of $\beta$-catenin is involved in the VEGF-induced permeability. Interestingly, blocking sGC improves high tidal volume ventilator-induced endothelial barrier function. These mice with ventilator-induced lung injury exhibit high cGMP and low cAMP levels, and treatment with iloprost improves vascular leak (Thibeau 2010, Schmidt 2008, Birukova 2010). Thus, cGMP and cAMP levels appear to have opposing effects on endothelial barrier function.

Activated protein $\mathrm{C}$ (APC), a plasma serine protease that forms a complex with EC protein $\mathrm{C}$ receptor (EPCR) is a cytoprotective agent functioning as an anticoagulant and profibrinolytic factor, and it participates in anti-inflammatory responses. In addition, EPCR has been shown to support APC-induced protease-activated receptor (PAR)-1-mediated cell signaling. APC via EPCR inhibits RhoA activation, increases Rac1 expression and inhibits vascular permeability. In support of this view, recent studies have shown reduced expression of EPCR and reciprocal increase in the expression of Rho associated kinase (ROCK)1 in a mouse model of ventilation-induced lung injury; and the treatment with APC restored the EPCR expression, attenuated ROCK1 expression and inhibited capillary leak (Baes 2007, Sen 2011, Finigan 2009). Interestingly, both thrombin and APC activate PAR1 with opposing effects. APC-induced PAR1 is cytoprotective whereas thrombin-induced PAR1 activation stimulates RhoA/ROCK, actin stress fiber formation, and alters the integrity of EC layer. Localization of APC-activated PAR1 and EPCR in caveolae is essential for the cytoprotective effects, but for thrombin-activated PAR1 caveolar localization is not necessary. APC treatment inhibits thrombin-induced activation of ERK1/2, whereas in caveolin-1-deficient EC, APC treatment does not prevent thrombin-induced ERK1/2 activation (Russo 2009, Carlisle-Klusack 2007). These studies underscore the importance of EC including endothelial caveolin-1 in maintaining vascular health.

\subsection{Inflammation}

It is well established that inflammation plays a significant role in the pathogenesis of $\mathrm{PH}$. Inflammation is an orchestrated process designed to combat injury/infection. The relevance of endothelium in controlling and modulating inflammatory responses in general is accepted. Under normal conditions, the apoptosis rate in EC is extremely low. Activated EC exhibit a reduction in the endothelial surface layer, glycocalyx, and increased rate of apoptosis. EC detached from the basement membrane appear in blood circulation. Therefore, it is not surprising that increased circulating endothelial cell levels in $\mathrm{PH}$ are indicative of poor prognosis (Grange 2010, Jones 2005, Smadja 2010). Both NO and ROS are implicated in the EC response to inflammation. Increased NO levels compared to ROS results in anti-inflammatory response via cGMP pathway, whereas, increased levels of ROS and/or the presence of reactive NO species activate proinflammatory transcription factors (Grange 2010).

In response to infection and inflammatory mediators, EC secrete increased amounts of Interleukin (IL)-6, and upregulate intracellular adhesion molecule (ICAM) and vascular adhesion molecule (VCAM), which spread over the surface of EC. ICAM, VCAM and also Pselectin released from Weibel Palade bodies allow rapid rolling and adhesion of leukocytes 
on the EC surface; and biosynthesized E-selectin maintains this process. Interaction of leukocyte platelet endothelial cell adhesion molecule-1 (PECAM-1) and EC PECAM-1 leads to transmigration of leukocytes through the inter EC junction and possibly through EC as well. Furthermore, stimulation of ICAM leads to VE-cadherin phosphorylation resulting in destabilization of AJ, thus further facilitating transmigration of leukocytes (Jirik 1989, Grange 2010, Muller 2009, van Buul 2007). IL-6 plays an important role in inflammatory response, thus, is critical for the acute phase response. It is believed that IL-6 resolves acute phase response and promotes acquired immune responses, which is controlled by chemokine-directed leukocyte recruitment but also by efficient activation of leukocyte apoptosis. IL-6-driven STAT3 activation is thought to limit the recruitment of neutrophils as well as pro-inflammatory cytokine. However, IL-6 also rescues cells from apoptosis via the activation of STAT3, and increased expression of anti-apoptotic factors such as Bcl-xL and $\mathrm{Bcl}_{2}$ (Jones 2005, Fielding 2008). In addition, the expression of isoforms of ROCK is increased. Inhibition of ROCK is thought to impair IL-6-mediated resolution of neutrophils-dependent acute inflammation (Mong 2009). Thus, IL-6 can function as an anti-inflammatory or a proinflammatory factor.

Deregulated IL-6/STAT3 pathway underlies a number of vascular diseases including PH, autoimmune diseases and cancer (Mathew 2004, Huang 2008, Hirano 2010, Yu 2009). In addition, the loss of caveolin-1 has been reported in theses cases. Caveolin- 1 is known to inhibit PY-STAT3 activation as well as the expression of $\mathrm{Bcl}-\mathrm{xL}$ and $\mathrm{Bcl}_{2}$. Caveolin-1 also inhibits and degrades inflammatory and pro-neoplastic protein COX2 (Mathew 2004, Huang 2010, Mathew 2011b, Mathew 2007). Caveolin-1 modulates inflammatory processes via its regulatory effect on eNOS, and depending on the cell type and context of the disease, the effect can be positive or negative.

Hemoxygenase (HO)-1, one of the isoenzymes has emerged as an important player in cellular defense mechanism. HO-1 catalyzes the metabolism of free heme into equimolar ferrous iron, carbon monoxide (CO) and biliverdin. The latter is converted to bilirubin by biliverdin reducatse. HO-1 suppresses inflammation by removing pro-inflammatory molecule, heme, and by generating $\mathrm{CO}$. $\mathrm{CO}$, biliverdin and bilirubin have cytoprotective function. HO-1/CO inhibits pro-inflammatory cytokines such as CCL2 and IL-6, and increases the production of IL-10 an anti-inflammatory cytokine. Interestingly, HO-1 and biliverdin reducatse are compartmentalized in endothelial caveolae; and similar to eNOS, HO-1 activity is inhibited by caveolin-1. CO has been shown also to activate sGC (Durante 2011, Pae 2009, Liang 2011).

\subsection{Coagulation and thrombosis}

In health, endothelium prevents thrombosis via a number of endothelium-derived inhibitors of coagulation such as thrombomodulin, protein $S$, heparin sulfate proteoglycans and tissue plasminogen activator (tPA). In addition, $\mathrm{PGI}_{2}, \mathrm{NO}$ and CD39 inhibit platelet aggregation. Released tPA catalyzes the conversion of plasminogen to plasmin thus, facilitating proteolytic degradation of thrombus (Oliver 2005). Activation of coagulation cascade is necessary for normal hemostasis. Tissue factor (TF) is a transmembrane glycoprotein that initiates coagulation cascade; and thrombin is the key effector enzyme for the clotting process. The coagulation cascade is activated to stop the blood loss by forming a clot (Shovlin 2010). TF, a member of cytokine superfamily that functions as high affinity receptor 
and a cofactor for plasma factors VII/VIIa, the initiator of blood coagulation. TF is not expressed in EC, but it is rapidly induced by infection and inflammatory cytokines (TNFa, IL-1 $\beta$ ). VEGF, a major stimulator of angiogenesis, is known to upregulate TF expression in EC (Mechtcheriakova 1999). Following injury/infection, Weibel Palade bodies fuse with endothelial cell membrane and release vWF, P-selectin and IL-8. Interestingly, capillary EC lack Weibel Palade bodies but they do express vWF, P-selectin, thus, are capable of participating in coagulation process. The inter-activation of vWF multimers with exposed subintimal matrix results in adherence to activated platelets and participation in clot formation. The release of P-selectin facilitates neutrophil adherence to EC and transmigration (Ochoa 2010).

It is well accepted that there are cross-talks between inflammatory responses and thrombosis. Coagulation has been shown to augment inflammatory responses, and anticoagulants blunt the coagulation-induced inflammatory responses. Furthermore, PGI2 and APC inhibit injury-induced $\mathrm{Ca}^{2+}$ flux and NFKB activation, and reduce significantly the expression of proinflammatory cytokines such as TNFa, IL-6 and IL-8. EPCR augments APC by thrombin/thrombomodulin complex; but EPCR is shed from EC by inflammatory mediators and thrombin, thus favoring thrombosis (Esmon 2001).

Under physiological state, circulating platelets are in a quiescent state, and the activation is inhibited by endothelium-derived $\mathrm{NO}$ and $\mathrm{PGI}_{2}$. Platelets are recruited early to the site of inflammation/injury to provide rapid protection from bleeding; however, they contribute both to coagulation and inflammation. Platelets form a layer, and vWF plays a critical role in the adherence of platelets to the injury site. At the site of adherence, platelets release platelet activating factors such as adenosine diphosphate (ADP), thromboxane A2 (TxA2), serotonin, collagen and thrombin. Thrombin is the most potent thrombogenic factor. In addition, release of ADP and TxA2 from platelets increases the expression of P-selectin and CD40 ligand (Angeolillo 2010). CD40, the receptor for CD40 ligand, is found on a number of cells including EC, macrophages, B-cells and vascular SMC. The interaction between CD40 and its ligand causes severe inflammatory responses, matrix degradation and thrombus formation; and it has been implicated in the pathogenesis of PH. Platelet-derived member of TNF superfamily "lymphotoxin-like inducible protein that competes with glycoprotein D for herpes virus entry mediator on T lymphocytes" (LIGHT) levels in serum are increased in patients with PAH; interestingly, LIGHT levels are not altered in PH secondary to left heart failure. LIGHT increases the expression of TF and plasminogen activator inhibitor (PAI)-1, and decreases thrombomodulin levels, thus, making EC pro-thrombogenic (Otterdal 2008). PAI-1, a potent endogenous inhibitor of fibrinolysis, is produced by several cells including EC. ROS has been shown to have a significant role in cytokine-induced increase in PAI-1 expression. Increased levels of PAI-1 enhance thrombosis and impair fibrinolysis. Recent studies suggest that PAI-1 regulates EC integrity and cell death. Increased levels are thought to confer resistance to apoptosis and facilitate cell proliferation (Jaulmes 2009, Balsara 2008, Schneider 2008).

\subsection{Angiogenesis}

The formation of new capillaries from a preexisting vessel is called angiogenesis. Angiogenesis plays a pivotal role in a numerous physiological and pathological processes such as organ development, tissue repair and carcinogenesis. Angiogenesis is controlled by 
opposing angiogenic and angiostatic factors. Some of the angiogenic factors are VEGFs, fibroblast growth factor (FGF)s, angiopoietins, PECAM-1, integrins, and VE-cadherin, and the angiostatic factors are angiostatin, endosatstin and thrombospondin (Distler 2003). Angiogenic factors such as angiopoietins 1 and 2 (Ang 1 and Ang 2), and VEGF orchestrate EC proliferation, migration and new blood vessel formation. These angiogenic factors also participate in inflammatory responses and barrier function. VEGFA is a major regulator of angiogenic signaling and functions through a tyrosine kinase receptor, VEGFR-2, found on the surface of EC. Downstream effector of VEGF-induced angiogenesis is eNOS. Not surprisingly, angiogenesis is impaired in eNOS knockout mice and the inhibition of eNOS antagonizes VEGF-induced angiogenesis. NO induces the expression of $\operatorname{av} \beta 3$ integrin, and the synthesis and release of collagen IV (a major component of endothelial basement membrane) from EC. Binding of these two molecules leads to the activation of integrin, facilitating cell adhesion, migration, cell proliferation and protection of EC from apoptosis (Ziche 1997, Wang 2011). vWF modulates angiogenesis via multiple pathways involving av $\beta 3$ integrin (a receptor for vWF on EC), VEGFR-2 signaling and Ang2. Inhibition of vWF in-vitro has been shown to increase angiogenesis, to increase VEGFR-2-dependent cell proliferation and migration associated with reduction in av $\beta 3$ integrin and increased Ang2 levels (Starke 2011). VE-cadherin not only mediates inter-endothelial cell adhesion but also controls VEGF-mediated EC survival and angiogenesis via pathways involving $\beta$-catenin, PI3 kinase and VEGFR-2. Deficiency of VE-cadherin results in the failure of transmission of VEGF-induced survival signaling to Akt kinase and $\mathrm{Bcl}_{2}$, resulting in apoptosis of EC (Carmeliet 1999).

Tie2, an endothelium-specific tyrosine kinase receptor and its ligand Ang1 and Ang2 are modulators of vascular development and angiogenesis. Ang1 does not promote EC proliferation but supports EC survival, maturation and stabilization of the new vessels formed by the activity of VEGF. In addition, Ang1 administration protects adult vasculature from leakage and Ang1 over-expressing mice are resistant to VEGF-induced vascular leak (Thurston 2000). Although Ang2 has been thought to counteract Ang1 and Tie2 activity, the recent studies show that Ang2 in the presence of VEGF supports EC survival and angiogenesis. EC death increases when Ang2 is injected with VEGF blocker (Lobov 2002). Thus, the presence or the absence of VEGF determines how Ang2 modulates EC survival. Recent studies show that both Ang1 and Ang2 have similar agonistic capacity to mediate endothelial P-selectin translocation, neutrophils adhesion and inflammatory response. Furthermore, both can activate Tie2 receptor on neutrophils (Lemieux 2005).

Interestingly, caveolin-1 deficient mice exhibit increased microvascular permeability and angiogenesis. EC from caveolin-1 null mice show increased tyrosine phosphorylation of VEGFR-2 and decreased association with VE-cadherin. The increased permeability and angiogenesis in caveolin-1 null cells may also be related to increased eNOS activity (Lin 2007, Chang 2009). Thus, the loss of inhibitory function of caveolin-1 on VEGFR-2 phosphorylation coupled with increased eNOS activity may accentuate permeability and angiogenesis.

\section{Endothelial injury and pulmonary hypertension}

From the foregoing sections, it is clear that EC orchestrates a complex metabolic machinery involving a number of signaling molecules to maintain vascular health. These multiple 
signaling pathways cross talk at different levels to preserve normal function and cell survival. Dysregulation of one signaling pathway has a profound effect on the other pathways, resulting in a cascade of events including deregulation of multiple pathways, impaired vascular relaxation, and the loss of barrier function, transmigration of neutrophils, thrombo-embolic phenomenon, cell proliferation and anti-apoptosis leading to vascular diseases including PH. Injurious stimuli such as inflammatory cytokines, increased shear stress, drug toxicity, hypoxia and exposure to reactive oxygen species, ventilation-induced lung injury lead to the loss of protective function of EC. The end results are an imbalance between vasodilatation and vasoconstriction, coagulation and fibrinolysis, and between cell proliferation and apoptosis.

In response to infection, inflammatory mediators or oxidant stress, EC lose barrier function, develop coagulation abnormities, secrete increased amounts of IL-6 and RANTES, express adhesion molecules and chemokines that promote adhesion and transmigration of leukocytes, and activate pro-proliferative and anti-apoptotic pathways. IL-6, a 20-30 kD glycoprotein, produced by several types of cells including macrophages, EC, vascular SMC, is induced in response to stress. It is a potent, inflammatory cytokine that plays a central role in host-defense mechanisms. IL-6 has been shown to induce proliferation of SMCs in a dose dependent manner. Increased levels of IL- 6 have been reported in clinical and experimental forms of PH. Furthermore, IL-6 is also thought to contribute to PH complicating chronic obstructive pulmonary disease. Recent studies show that the increased levels of IL-6 portend poor prognosis in patients with PAH (Humbert 1995, Mathew 2010, Soon 2010). During the inflammatory response, upregulated IL-6 binds to gp130, a plasma membrane receptor complex that colocalizes with caveolin-1, to activate Janus kinase (JAK), a tyrosine kinase family member leading to PY-STAT3 activation, a downstream effector of IL-6. The downstream signaling molecules of PY-STAT3 such as Bcl-xL, survivin and cyclin D1 are implicated in PAH. In addition, pulmonary EC obtained from patients with idiopathic PAH show activation of STAT3. Recent studies have shown that caveolin-1 inhibits STAT3 activation, and the rescue of caveolin-1 not only inhibits PY-STAT3 activation but also attenuates MCT-induced PH (Mathew 2010, Huang 2010, Masri 2007, Mathew 2007, Huang 2008). The initial inflammatory response is an attempt to repair the injury. But as IL6/STAT3 pathway becomes deregulated, the results are further EC damage, increased cell proliferation and disruption of barrier function leading to vascular remodeling and $\mathrm{PH}$.

Depending on the type of injury, the major effect on EC is either a progressive loss of cell membrane integrity coupled with the loss of endothelial caveolin-1 and other EC proteins, or caveolin-1 dysfunction without any protein loss. In either case the end results are impaired endothelium-dependent vascular relaxation, medial hypertrophy, narrowing of the lumen, elevated pulmonary artery pressure and right ventricular hypertrophy.

\subsection{Endothelial cell disruption}

\subsubsection{Loss of endothelial caveolin-1}

Injury such as inflammation, chemical/drug toxicity, ventilation-induced lung injury and cyclic shear stress disrupt endothelial membrane integrity. Monocrotaline (MCT), an inflammatory model of $\mathrm{PH}$ has been extensively studied. Although this model is not exactly akin to the human from of $\mathrm{PH}$, nevertheless, it has provided valuable information. In this 
model, disruption of caveolae, progressive loss of caveolin-1, reciprocal activation of PYSTAT3 and upregulation of Bcl-xL are observed within $48 \mathrm{hrs}$ of MCT injection, i.e. before the onset of PH. Other EC membrane proteins such as PECAM-1 and Tie2 are lost in tandem with caveolin-1. At 2 wks post-MCT, with the onset of $\mathrm{PH}$, there is a further loss of proteins such as HSP90, Akt, and IKB-a. The eNOS expression is relatively well preserved, but with transient eNOS uncoupling as indicated by increased ROS generation. Furthermore, at this stage, impaired NO bioavailability, low cGMP and sulfhydryl levels have been observed. By 3-4 wks post-MCT, there is a significant reduction in the expression of eNOS protein, and ROS generation returns to normal level. Early treatment with anti-inflammatory agents prevents the loss of endothelial caveolin-1, inhibits the activation of proliferative pathways and attenuates $\mathrm{PH}$; however, once the $\mathrm{PH}$ is established, these agents are not effective (Mathew 2007, Huang 2008, Huang 2010). Caveolin-1 null mice exhibit vascular defect and cardiomyopathy with a propensity to develop $\mathrm{PH}$; rescue of caveolin-1 ameliorates cardiovascular function and attenuates PH (Murata 2007). Loss of endothelial caveolin-1 has also been reported in idiopathic PAH (Achcar 2006, Patel 2007, Mathew 2011a). Thus, there is a strong evidence that endothelial caveolin-1 has a pivotal role in PH. Endothelial caveolin-1 regulates inflammatory response, proinflammatory cytokines, inhibits a number of mitogens implicated in $\mathrm{PH}$, and it controls cell proliferation and apoptosis. Thus, the loss of endothelial caveolin-1 is sufficient to initiate $\mathrm{PH}$ and facilitate the progression of the disease.

\subsubsection{Enhanced expression of caveolin-1 in SMC}

Recently it was reported that in addition to the loss of endothelial caveolin-1, pulmonary arterial SMC from patients with idiopathic PAH exhibited enhanced expression of caveolin1. These SMC with enhanced expression of caveolin-1 exhibited altered $\mathrm{Ca}^{2+}$ handling, increased cytosolic $\left[\mathrm{Ca}^{2+}\right]_{\mathrm{i}}$ and increased DNA synthesis. Increased $\left[\mathrm{Ca}^{2+}\right]_{i}$ is a trigger for DNA synthesis and cell proliferation (Patel 2007). In patients with chronic obstructive pulmonary disease (COPD), enhanced expression of caveolin-1 in SMC correlates with the presence of PH (Huber 2009). Recently it was reported that a child developed PH about 2 years after having completely recovered from acute respiratory distress syndrome (ARDS). It is well established that underlying pathology of ARDS is pulmonary vascular endothelial damage. At the time of the diagnosis of $\mathrm{PH}$, pulmonary arteries exhibited loss of endothelial caveolin-1 and medial wall thickening. Importantly, the arteries that exhibited loss of endothelial caveolin-1 coupled with the loss of vWF had robust expression of caveolin-1 in SMC; whereas, the arteries that exhibited endothelial caveolin- 1 loss alone did not have enhanced expression of caveolin-1 in SMC. Second lung biopsy done 3 years later exhibited neointima formation and by then the vasculature had become unresponsive to therapy (Mathew 2011a). These results suggest that the initial EC injury during ARDS was progressive although not clinically apparent. Since vWF is stored in Weibel Palade bodies within the EC, the loss of VWF is indicative of an extensive endothelial damage and/or loss. Therefore, it is not surprising that increased plasma levels of vWF and Ang2, and circulating endothelial cells in PAH are considered markers of poor prognosis (Kawut 2005, Kümpers 2010, Smadja 2010). It is worth noting here that both vWF and Ang2 are stored in Weibel Palade bodies and during stress/activation, these bodies deliver their cargo at the endothelial cell surface. 
Caveolin-1 is essential for normal functioning of SMC. Under normal circumstances, caveolin-1 inhibits receptor and non-receptor tyrosine kinases by sequestering them to caveolae and prevents cell proliferation. Disruption of caveolin-1 has been shown to increase cell proliferation in airway and vascular SMC. Caveolin-1 keeps mitogens inactive in caveolae; however, under increased mechanical stress/strain, caveolin-1 translocates from caveolae to non-caveolar sites within the plasma membrane of cultured SMC, and translocated caveolin-1 triggers cell cycle progression and cell proliferation (Gosens 2006, Hassan 2006, Kawabe 2004, Mathew 2011b). It has also been shown that cultured cells (murine lung endothelial and HeLa cells) exposed to mechanical stress exhibit reduction in caveolin-1 and cavin-1 (also known as polymerase 1 and transcript release factor) interaction, disappearance of caveolae and increased expression of caveolin-1 at the plasma membrane. Importantly, caveolin-1 requires cavin for caveolae formation [Sinha 2011, Mathew 2011b). From these studies it appears that the progressive EC damage and the eventual loss expose underlying SMC to blood elements and cyclic shear stress, leading to enhanced expression of caveolin-1 and its translocation from caveolae. It is worth noting here that the activation of matrix metalloproteinases (MMP) 2 is a critical step in the migration of SMC through the basement barrier, which facilitates neointima formation. Increased expression and activity of MMP2 has been reported in SMC from patients with idiopathic PAH. MMP2 and its physiologic activator MT1-MMP colocalize in caveolae and are negatively regulated by caveolin-1 [Mathew 2011b). These observations further support the view that SMC exposed to increased shear stress may translocate caveolin-1 from caveolae to other plasma membrane sites, thus losing its inhibitory activity on MT1-MMP and MMP2, thus, facilitating cell migration via MMP2.

Increased eNOS expression and PKG nitration have been shown in caveolin-1 null mice and also in the lungs of patients with idiopathic PAH contributing to the worsening of the disease. The expression of eNOS is reported to be either low or increased in the lungs of patients with $\mathrm{PH}$. This is not surprising because the disease does not progress uniformly, the expression of eNOS depends on the stage of disease in a given lung section. In PH, the initial loss of EC is followed by the appearance of apoptosis resistant EC. These neointimal EC have increased expression of eNOS and reduced expression of caveolin-1, thus, resulting in uncoupling of eNOS, oxidant and nitration injury [Mathew 2011b).

As shown in Figure 1, the sequel of EC injury (shear stress, drug toxicity, inflammation) can be summarized as follows: 1) a progressive disruption of EC membrane integrity and the loss of endothelial caveolin-1,2) impaired $\mathrm{Ca}^{2+}$ entry into EC resulting in reduced production of $\mathrm{NO}, \mathrm{PGI}_{2}$ and EDHF leading to impaired vascular relaxation, 3) activation of proliferative and antiapoptotic pathways leading to vascular cell proliferation, medial wall thickening and $\mathrm{PH}$. As the disease progresses, further loss of proteins occurs indicating extensive EC damage/loss. This is followed by enhanced expression of cav-1 in SMC, where cav-1 facilitates cell proliferation and migration leading to neointima formation. Thus, the translocated caveolin-1 in SMC not only loses its ability to inhibit proliferative pathways but also switches from being antiproliferative to proproliferative that may eventually lead to SMC phenotype change from contractile to synthetic. Recent studies indicate that there is increased expression of eNOS in neointimal EC; but eNOS is dysfunctional, resulting in oxidant/nitration injury thus further aggravating PH (Mathew 2011b). 


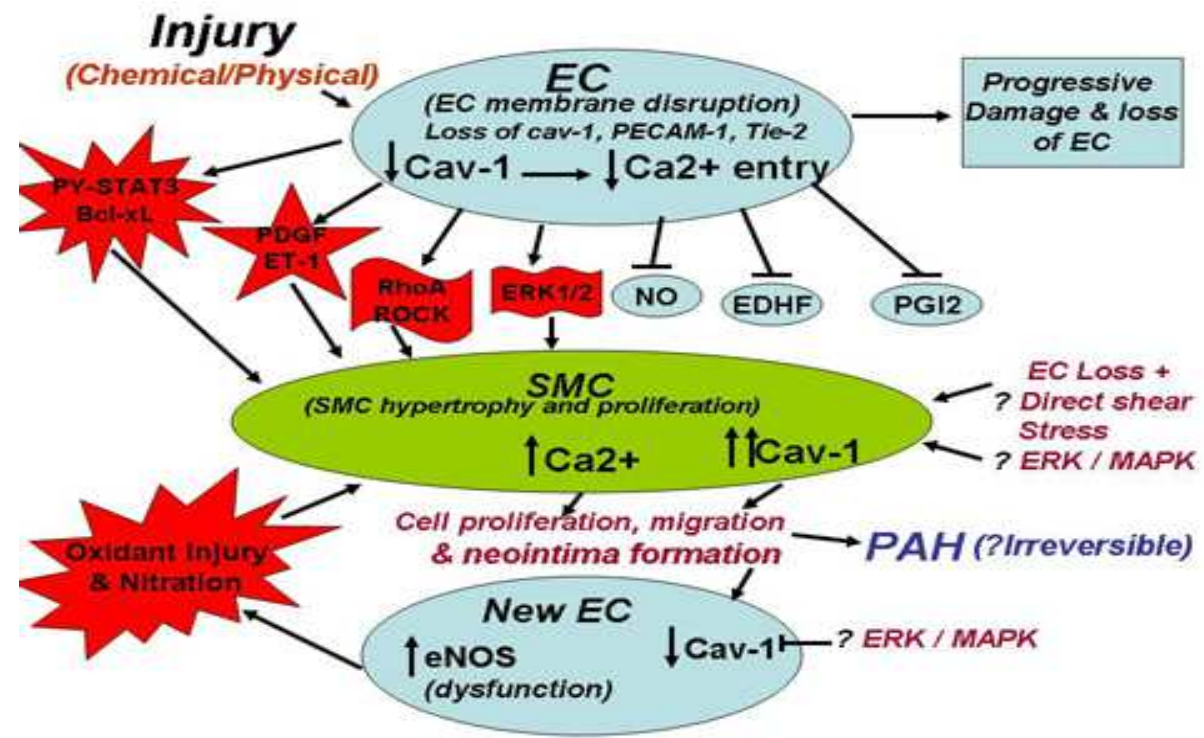

Fig. 1. Adapted from Mathew R, Pulmonary Medicine 2011; 2011:57432. A proposed model for $\mathrm{PH}$ associated with disruption of endothelial caveolin-1 resulting in the loss of vasodilators, and the activation of proliferative and anti-apoptotic pathways leading to pulmonary vascular remodeling. EC disruption is progressive and extensive damage/ loss of EC exposes SMC to direct shear stress leading to enhanced expression of caveolin- 1 in SMC which participates in further cell proliferation and cell migration resulting in neointima formation. Newly formed EC in neointima express increased eNOS; low caveolin-1 expression in these cells may in part be responsible for the observed dysfunctional eNOS. Resulting oxidant/nitration injury may further influence SMC adversely leading to irreversible $\mathrm{PH}$.

\subsection{Endothelial dysfunction without caveolin-1 loss}

$\mathrm{PH}$ is an important cause of increased mortality in patients suffering from chronic heart diseases associated with hypoxia. Acute hypoxia causes reversible pulmonary vasoconstriction and $\mathrm{PH}$. Chronic hypoxia causes vasoconstriction with subsequent vascular remodeling and sustained $\mathrm{PH}$. Not unlike MCT-induced $\mathrm{PH}$, hypoxia-induced $\mathrm{PH}$ is associated with low bioavailability of $\mathrm{NO}$ and impaired endothelium-dependent pulmonary vascular relaxation. In contrast to the MCT model, in the hypoxia model there is no loss of eNOS, caveolin-1 or HSP90 proteins (Huang 2010, Mathew 2011b). Pulmonary arteries of rats with hypoxia-induced $\mathrm{PH}$ reveal that eNOS forms a tight complex with caveolin-1, and becomes dissociated from HSP90 and calmodulin, resulting in eNOS dysfunction. Bovine pulmonary artery EC exposed to hypoxia also exhibit tight coupling of eNOS and caveolin-1 accompanied by PY-STAT3 activation. Since caveolin-1 inhibits PY-STAT3 activation, the activation of PY-STAT3 in hypoxia-induced PH despite the unaltered expression of caveolin-1 protein indicates that caveolin-1 has lost its inhibitory function (Huang 2008, Mathew 2011b, Murata 2002). Thus, this complex formation renders both eNOS and 
caveolin-1 dysfunctional. Statins therapy has shown to protect eNOS function in hypoxiainduced $\mathrm{PH}$. The major effect of statins is reported to be the uncoupling of eNOS/caveolin-1 complex, thus, freeing eNOS for activation (Murata 2005). Therefore, it is likely that the statins disrupt the tight cavolin-1/eNOS coupling, resulting from hypoxia- induced perturbation of EC membrane, thus, restoring antiproliferative properties of caveolin- 1 and NO production by eNOS. Unlike the MCT model, hypoxia does not appear to cause physical disruption of EC membrane, but causes perturbation of the EC membrane leading to "mislocalization" of caveolin-1 and eNOS. As depicted in Figure 2, hypoxia induces tight complex formation of eNOS and caveolin-1 resulting in dysfunction of both molecules leading to impaired availability of NO, increased ROS production and activation of proliferative pathways, thus facilitating increased medial wall thickness and $\mathrm{PH}$. It is important to note that unlike the MCT model, there is no loss of eNOS or caveolin-1 protein in the hypoxia model.

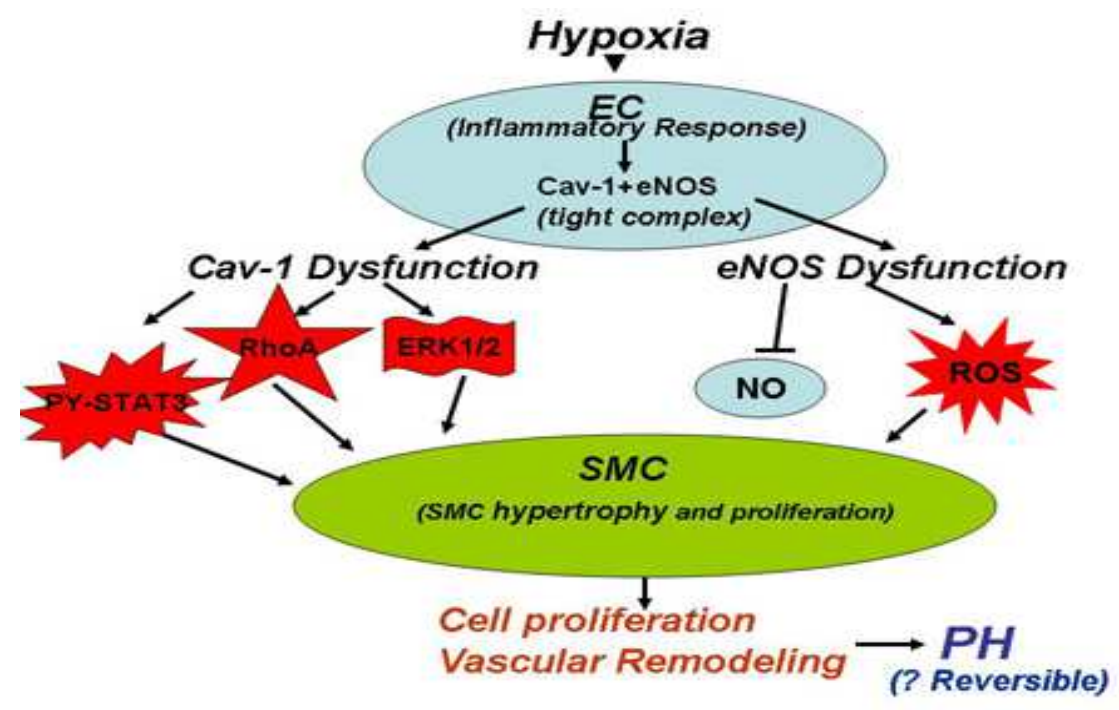

Fig. 2. Adapted from Mathew R, Pulmonary Medicine 2011; 2011:57432. Hypoxia-induced perturbation of endothelial cell membrane results in a tight complex formation of caveolin-1 and eNOS, rendering both molecules dysfunctional leading to low NO bioavailability and superoxide generation; and the loss of ability of caveolin-1 to inhibit proliferative pathways.

\section{Therapeutic potential}

Since the introduction of vasodilators and anti-mitogenic therapy, there has been a significant improvement in exercise tolerance and life expectancy in patients with $\mathrm{PH}$ compared with the historical controls. However, there is no cure; the disease is progresses albeit at a slower rate. Currently approved therapy belongs to 3 major groups: 1) $\mathrm{PGI}_{2}$ analogues: $\mathrm{PGI}_{2}$ remains the mainstay in the treatment of $\mathrm{PH}$. Synthetic $\mathrm{PGI}_{2}$ used as 
continuous infusion has been found to be efficacious in several forms of PH. Other synthetic analogues for use via oral and subcutaneous routes are available. 2) ET-1 blockers: ET-1 is a potent vasoconstrictor with mitogenic and inflammatory properties; and it functions both in paracrine and autocrine fashion. The effects of ET-1 are mediated through ETA and ETB receptors. Bosentan, a sulfonamide-based dual endothelin receptor antagonist has been in use for the treatment of $\mathrm{PH}$. Several studies have shown improvement in hemodynamic parameters, exercise tolerance and the time to clinical worsening in patients with PAH. One of the important side effects of bosentan is abnormal liver function tests. Ambrisentan, a propanoic-based ET-1 receptor blocker seems to have much lower incidence of liver function abnormalities. 3) PDE5 inhibitors: PDE5 inhibitors block the conversion of cGMP to 5' GMP. Sildenafil is the most commonly used drug in this group. These drugs are used as monotherapy or in combination. Newer drugs such as soluble guanylate cyclase activators, tyrosine kinase inhibitors are being tested (Rhodes 2009, Stenmark 2009).

Endothelial progenitor cells (EPC) and gene therapy are being actively pursued. However, the vectors and gene delivery systems still need to be refined (Reynolds 2011). Several experimental studies with EPC/gene therapy have shown encouraging results. Administration of bone-derived EPC transduced with eNOS was found to be effective in reversing the disease process in established MCT-induced $\mathrm{PH}$, but EPC administration had no effect on hypoxia-induced PH (Zhao 2005, Raoul 2007). In contrast, BMPRII gene therapy attenuated hypoxia-induced PH but had no effect on MCT-induced PH (Reynolds 2009, McMurtry 2007). The MCT model is associated with progressive loss of endothelial cell membrane integrity leading to extensive EC damage and/or loss; whereas, hypoxia does not cause EC loss. These studies raise important questions: 1) whether the state of native EC is important in selecting EPC transduced with the desired gene or the vector-driven gene therapy, or 2) these results are simply related to the efficacy of the genes in question. An ideal treatment would be to tailor the EPC/gene therapy for individual patients. A combination of gene therapy and pharmacological agents may be able to reverse the disease or at least halt the progression.

\section{Summary}

EC with specialized membrane rafts and organelles conduct a fine orchestra with multiple interacting sections (signaling pathways) to produce harmonious music (vascular health). Events such as injury/inflammation/shear stress leading to one false note, if not repaired early, leads to utter chaos, and the recovery becomes almost impossible. In response to injury, several signaling pathways are activated in an attempt to repair the damage. However, these pathways do become deregulated and the cytoprotective molecules become cytotoxic leading to the loss of barrier function, vasodilatation mechanisms, and the activation of cell proliferative and antiapoptotic pathways. Current therapy is based on individual signaling pathways. A holistic approach to recover EC function may be an attractive strategy to pursue for the treatment of $\mathrm{PH}$.

\section{References}

Achcar RO, Demura Y, Rai PR, Taraseviciene-Stewart L, Kasper M et al. Loss of caveolin and heme oxygenase expression in severe pulmonary hypertension. Chest 2006; 129:696705 . 
Angiolillo DJ, Ueno M, Goto S. Basic principles of platelet biology and clinical implications. Circ J 2010; 74:597-607.

Atkinson C, Stewart S, Upton PD, Machado R, Thomson JR et al. Primary pulmonary hypertension is associated with reduced pulmonary vascular expression of type II bone morphogenic protein receptor. Circulation 2002; 105:1672-1678.

Austin ED, Cogan JD, West JD, Hedges LK, Hamid R et al. Alterations in oestrogen metabolism: Implications for higher penetrance of familial pulmonary arterial hypertension in females. Eur Respir J 2009; 34:1093-1099.

Baes JS, Yang L, Manithody C, Rezaie AR. The ligand occupancy of endothelial protein C receptor switches the protease activated receptor-dependent signaling specificity of thrombin from a permeability-enhancing to a barrier -protective response in endothelial cells. Blood 2007; 110:3909-3916.

Balabanian K, Foussat A, Dorfmüller P, Durand-Gasselin I, Capel F et al. $\mathrm{CX}_{3} \mathrm{C}$ chemokine fractalkine in pulmonary arterial hypertension. Am J Respir Crit Care Med 2002; 165:1419-1425.

Balsara RD, Ploplis VA. Plasminogen activator inhibitor-1: the double edged sword in apoptosis. Thromb Haemost 2008: 100:1029-1036.

Birukova AA, Fu P, Xing J, Cokie I, Birukov KG. Lung endothelial barrier protection by iloprost in the two-hit models of ventilator-induced lung injury (VILI) involves inhibition of Rho signaling. Transl Res 2010; 155:44-54.

Brock M, Trenkmann M, Gay RE, Michel BA, Gay S et al. Interleukin 6 modulates the expression of the bone morphogenic protein receptor type II through a novel STAT3 micro RNA cluster 17/29 pathway. Circ Res 2009;104:1184-1191.

Carlisle-Klusack ME, Rizzo V. Endothelial cytoskeleton reorganization in response to PAR1 stimulation is mediated by membrane rafts but not caveolae. Am J Physiol 2007; 293:H366-H375.

Carmeliet P, Lampugnani MG, Moons L, Breviario F, Compernolle V et al. Targeted deficiency or cytosolic truncation of the VE-cadherin gene in mice impairs VEGFmediated endothelial survival and angiogenesis. Cell 1999; 98:147-157.

Chang SH, Feng D, Nagy JA, Sciuto TE, Dvorak AM et al. Vascular permeability and pathological angiogenesis in caveolin-1-null mice. Am J Pathol 2009; 175:1768-1776.

Dejana E, Orsenigo F, Lamugnani MG. The role of adherens junctions and VE-cadherin in control of vascular permeability. J Cell Sci 2008; 121:2115-2122.

Distler JH, Hirth A, Kurowska-Stolarska M, Gay RE, Gay S et al. Angiogenic and angiostatic factors in the molecular control of angiogenesis. Q J Nuc Med 2003; 47:149-161.

Dorfmuller P, Perros F, Balabanian K, Humbert M. Inflammation in pulmonary arterial hypertension. Eur Respir J 2003; 22:358-363.

Dorfmüller P, Zarka V, Durand-Gasselin J, Monti G, Balabanian K et al. Chemokine RANTES in severe pulmonary arterial hypertension. Am J Respir Crit Care Med 2002;165:534-539.

Durante W. Protective role of hemoxygenase-1 against inflammation in atherosclerosis. Front Biosci 2011; 17:2372-2388.

Esmon CT. Role of coagulation inhibitors in inflammation. Thromb Hemost 2001; 86:51-56.

Fielding CA, McLoughlin RM, McLeod L, Colmont CS, Najdovska M et al. IL-6 regulates neutrophils trafficking during acute inflammation via STAT3. J Immunol 2008; 181:2189-2195. 
Finigan JH, Boueiz A, Wilkinson A, Damico R, Skirball J et al. Activated protein C protects against ventilator-induced pulmonary vascular leak. Am J Physiol 2009;296 L1002L1011.

Gosens R, Stelmark GL, Dueck G, McNeill KD, Yamasaki A et al. Role of caveolin-1 in p42/p44 Map kinase activation and proliferation of human airway smooth muscle. Am J Physiol 2006; 291:L523-L534.

Grange DN, Senchenkova E. Inflammation and microcirculation. Integrated system physiology: From cell to function. 2010 San Rafael (CA), Morgan Claypool Life Sciences.

Gratton JP, Fontana J, O'Connor DS, Garcia-Cardena G, McCabe TJ et al. Reconstitution of an endothelial nitric oxide synthase (eNOS), hsp90 and caveolin-1 complex in vitro. Evidence that hsp90 facilitates calmodulin stimulated displacement of eNOS from caveolin-1. J Biol Chem 2000; 275:22268-22272.

Hassan GS, Williams TM, Frank PG, Lisanti MP. Caveolin-1-deficient aortic smooth muscle cells show cell autonomous abnormalities in proliferation, migration, and endothelin-based signal transduction. Am J Physiol 2006; 290:H2393-H2401.

Hirano T. IL-6 in autoimmune and inflammatory diseases: A personal memoir. Proc Jpn Acad Ser B Phys Biol Sci 2010; 86:717-730.

Hoeper MM. Definition, classification, and epidemiology of pulmonary arterial hypertension. Semin Respir Crit Care Med. 2009; 30:369-375.

Huang J, Kaminski PM, Edwards JG, Yeh A, Wolin-MS et al. Pyrrolidine dithiocarbamate restores endothelial cell membrane integrity and attenuates monocrotaline-induced pulmonary artery hypertension. Am J Physiol 2008; 294:L-1250-L1259

Huang J, Wolk J, Gewitz MH, Mathew R. Progressive Endothelial Cell Damage in an Inflammatory Model of Pulmonary Hypertension. Exp Lung Res 2010; 36:57-66.

Huber LC, Soltermann A, Fischler M, Gay S, Weder W et al. Caveolin-1 expression and hemodynamics in COPD patients. Open Respir Med J 2009; 3:73-78.

Humbert M, Monti G, Brenot F, Sitbon O, Portier A et al. Increased interleukin-1 and interleukin-6 serum concentrations in severe primary pulmonary hypertension. Am J Respir Crit Care Med 1995; 151:1628-1631.

Itoh T, Nagaya N, Ishibashi-Ueda-H, Kyotani S, Oya H et al. Increased plasma monocyte chemoattractant protein-1 level in idiopathic pulmonary arterial hypertension. Respirology 2006;11:158-163.

Jaulmes A, Sansilvestri-Morel P, Rolland-Volognes G, Bernhardt F, Gaertner R et al. NOX4 mediates the expression of plasminogen activator inhibitor-1 via p38MAPK pathway in cultured endothelial cells. Thromb Res 2009; 124:439-446.

Jirik FR, Podor TJ, Hirano T, Kishimoto T, Loskutoff DJ et al. Bacterial lipopolysaccharide and inflammatory mediators augment IL-6 secretion by human endothelial cells. J Immunol 1989;142:144-147.

Jones SA, Directing transition from innate to acquired immunity: defining a role for IL-6. J Immunol 2005; 175:3463-3468.

Kawabe J, Okumura S, Lee MC, Sadoshima J, Ishikawa Y. Translocation of caveolin regulates stretch-induced ERK activity in vascular smooth muscle cells. Am J Physiol 2004; 286:H1845-H1852.

Kawabe J, Ushikubi F, Hasebe N. Prostacyclin in vascular diseases: Recent insight and future perspectives. Circ J 2010; 74:936-943. 
Kawamura C, Kizaki M, Yamato K, Uchida H, Fukuchi Y et al. Bone Morphogenic protein-2 induces apoptosis in human myeloma cells with modulation of STAT3. Blood 2000; 96:2005-2011.

Kawut SM, Horn EM, Berekashvili KK, Widitz AC, Rosezweig EB et al. von Willebrand factor independently predicts long-term survival in patients with pulmonary arterial hypertension. Chest 2005; 128:2355-2362

Kümpers P, Nickel N. Lukasz A, Golpon H, Westerkamp V et al. Circulating angiopoietins in idiopathic pulmonary arterial hypertension. Eur Heart J 2010; 31:2291-2230.

Lemieux C, Maliba R, Favier J, Théorêt JF, Merhi Y et al. Angiopoietins can directly activate endothelial cells and neutrophils to promote proinflammatory responses. Blood 2005; 105:1523-1530.

Lesprit P, Godeau B, Authier FJ, Soubrier M, Zuber M et al. Pulmonary hypertension in POEMS syndrome: a new feature mediated by cytokines. Am J Respir Crit care Med 1998; 157:907-911.

Liang OD, Mistialis SA, Chang MS, Vergadi E, Lee C et al. Mesenchymal stromal cells expressing heme oxygensase-1 reverses pulmonary hypertension. Stem Cells 2011; 29:99-107.

Lin MI, Yu J, Murata T, Sessa WC. Caveolin-1-deficient mice have increased tumor microvascular permeability, angiogenesis, and growth. Cancer Res 2007; 67:28492856.

Lobov IB, Brooks PC, Lang RA. Angiopoietin-2 displays VEGF-dependent modulation of capillary structure and endothelial cell survival in vivo. Proc Natl Acd Sci 2002; 99:11205-11210.

Long L, MacLean MR, Jeffery TK, Morecroft I, Yang X et al. Serotonin increases susceptibility to pulmonary hypertension in BMPR2-deficeint mice. Circ Res 2006; 98:818-827.

Machado R, Aldred MA, James V, Harrison RE, Patel B et al. Mutations of the TGF- $\beta$ type II receptor BMPR2 in pulmonary arterial hypertension. Hum Mutation 2006; 27:121132.

Masri FA, Xu W, Combair SA, Asosingh K, Koo M et al. Hyperproliferative apoptosisresistant endothelial cells in idiopathic pulmonary artery hypertension. Am J Physiol 2007; 293:L548-L554.

Mathew R, Huang J, Gewitz MH. Hypertension: caveolin-1 and eNOS Interrelationship: a new perspective. Cardiol Rev 2007; 15:143-149

Mathew R, Huang J, Katta UD, Krishnan U, Sandoval S et al. Immunosuppressant- induced endothelial damage and pulmonary arterial hypertension. J Ped Hem Onc 2011a; 33:55-58.

Mathew R, Huang J, Shah M, Patel K, Gewitz MH et al. Disruption of endothelial cells raft scaffolding during the development of monocrotaline-induced pulmonary hypertension. Circulation 101:1499-1506, 2004.

Mathew R. Cell specific dual role of caveolin-1 in pulmonary hypertension. Pulm Med 2011b; 2011: 573432

Mathew R. Inflammation and Pulmonary Hypertension. Cardiol Rev 2010; 18:67-72, 2010.

McDonald KK, Zharkovit S, Block ER, Kilberg MS. A caveolar complex between the cationic amino acid transporter 1 and endothelial nitric oxide synthase may explain the "arginine paradox". J Biol Chem 272:31213-31216, 1997. 
McMurtry MS, Moudgil R, Hashimoto K, Bonnet S, Michelakis ED et al. Overexpression of human bone morphogenetic protein receptor 2 does not ameliorate monocrotaline pulmonary arterial hypertension. Am J Physiol 2007; 292:L872-L828.

Mechtcheriakova D, Wlachos A, Holzmüller H, Binder BR, Hofer E. Vascular endothelial growth factor-induced tissue factor expression in endothelial cells is modulated by EGR-1. Blood 1999; 93:3811-3823.

Mehta D, Malik AB. Signaling mechanisms regulating endothelial permeability. Physiol Rev 2006; 86:279-367.

Metcalf DJ, Nightingale TD, Zenner H, Lui-Roberts WW, Cutler DF. Formation and function of Weibel Palade bodies. J Cell Sci 2008; 121:19-27.

Mong PY, Wang Q. Activation of Rho Kinase isoforms in lung endothelial cells during inflammation. J Immunol 2009; 182:2385-2394.

Muller WA. Mechanisms of trans-endothelial migration of leukocytes. Circ Res 2009; 105: 223-230.

Murakami K, Mathew R, Huang J, Farahani R, Peng H et al. Smurf-1 ubiquitin ligase causes downregulation of BMP receptors and is induced in monocrotaline and hypoxia models of pulmonary arterial hypertension. Expt Biol Med 2010; 235:805-813.

Murata T, Kinoshita K, Hori M, Kuwahara M, Tsubone H et al. Statin protects endothelial nitric oxide synthase activity in hypoxia-induced pulmonary hypertension. Arterioscler Thromb Vasc Biol 2005; 25:2335-2342.

Murata T, Lin MI, Huang Y, Yu J, Bauer PM et al. Reexpression of caveolin-1 in endothelium rescues the vascular, cardiac, and pulmonary defect in global caveolin-1 knockout mice. J Exp Med 2007; 204:2373-2382.

Murata T, Sato K, Hori M, Ozaki H, Karaki H. Decreased endothelial nitric oxide synthase (eNOS) activity resulting from abnormal interaction between eNOS and its regulatory proteins in hypoxia induced pulmonary hypertension. J Biol Chem 2002; 277:44085-44092.

Ochoa CD, Wu S, Stevens T. New developments in lung endothelial heterogeneity: von Willebrand factor, P-selectin and Weibel Palade body. Semin Thromb Hemost 2010; 36:301-308.

Oliver JJ, Webb DJ, Newby DE. Stimulated plasminogen activator release as a marker of endothelial function in humans. Arterioscl Thromb Vasc Biol 2005; 25:2470-2479.

Otterdal K, Andreassen AK, Yndestad A, Oie E, Sandberg WJ et al. Raised LIGHT levels in pulmonary arterial hypertension: potential role in thrombus formation. Am J Respir Crit Care Med 2008; 117:202-207.

Pae HO, Chung HT. Heme oxygenase -1: its therapeutic roles in inflammatory diseases. Immune Netw 2009; 9:12-19.

Patel HH, Zhang S, Murray F, Suda RY, Head BP et al. Increased smooth muscle cell expression of caveolin-1 and caveolae contribute to the pathophysiology of idiopathic pulmonary arterial hypertension. FASEB J 2007; 21:2970-2979.

Peterson TE, d'Uscio LV, Cao S, Wang XL, Katusic ZS. Guanosine triphosphate cyclohydrolase 1 expression and enzymatic activity are present in caveolae of endothelial cells. Hypertension 2009; 53:189-195.

Raoul W, Wagner-Ballon O, Saber G, Hulin A, Marcos E et al. Effects of bone marrowderived cells on monocrotaline- and hypoxia-induced pulmonary hypertension in mice. Respir Res 2007, 8:8 
Rath G, Dessy C, Feron O. Caveolae, caveolin and control of vascular tone: nitric oxide (NO) and endothelium-derived hyperpolarizing factor (EDHF) regulation. I Physiol Pharmacol 2009; 60 (suppl 4): 105-109.

Razani B, Wang XB, Engelman JA, Battista M, Lagaud G et al. Caveolin-2 deficient mice show evidence of severe pulmonary dysfunction without disruption of caveolae. Mol Cell Biol 2002; 22:2329-2344.

Reynolds AM, Xia W, Holmes MD, Hodges SJ, Danilov S et al. Bone morphogenetic protein type 2 receptor gene therapy attenuates hypoxia pulmonary hypertension. Am J Physiol 2009; 292:L1182-L1192.

Reynolds PN. Gene therapy for pulmonary hypertension: prospects and challenges. Expert Opin Biol Ther 2011; 11:133-143.

Rhodes CJ, Davidson A, Gibbs JS, Wharton J, Wilkins MR. Therapeutic targets in pulmonary hypertension. Pharmacol Therap 2009; 121:69-88.

Russo A, Soh UJ, Paing MM, Arora P, Trejo J. Caveolae are required for protease-selective signaling by protease-activated receptor-1. Proc Natl Acad Sci 2009; 106:6393-6397.

Saliez J, Bouzin C, Rath G, Ghisdal P, Desjardin F et al. Role of caveolar compartmentation in endothelium-derived hyperpolarizing factor-mediated relaxation: $\mathrm{Ca}^{2+}$ signals and gap junction function are regulated by caveolin in endothelial cells. Circulation 2008; 117:1065-1074.

Sanchez O, Marcos E, Perros F, Fadel E, Tu L et al. Role of endothelium-derived CC chemokine ligand 2 in idiopathic pulmonary arterial hypertension. Am J Resp Crit care Med. 2007; 176:1041-1047.

Schmidt EP, Damarla M, Rentsendorj O, Servinsky LE, Zhu B et al. Soluble guanylate cyclase contributes to ventilator-induced lung injury in mice. Am J Physiol 2008; 295:L1059-L1065.

Schneider DJ, Chen Y, Sobel BE. The effect of plasminogen activator inhibitor type-1 on apoptosis. Thromb Haemost 2008; 100:1037-1040.

Schubert W, Frank PG, Woodman SE, Hyogo H, Cohen DE et al. Microvascular hyperpermeability in caveolin-1 (-/-) knockout mice: Treatment with a specific nitric oxide synthase inhibitor L-NAME restores normal microvascular permeability in caveolin-1 null mice. J Biol Chem 2002; 277:40091-40098

Sen P, Gopalkrishnan R, Kothari H, Keshava S, Clark CA et al. Factor VIIa bound to endothelial cell protein $C$ receptor activates protease activated receptor-1 and mediates cell signaling and barrier function. Blood 2011; 117:3199-3208.

Sessa WC, Garcia-Cardena G, Liu J, Keh A, Pollock JS et al. The golgi association of endothelial nitric oxide synthase is necessary for the efficient synthesis of nitric oxide. J Biol Chem 1995; 270:17641-17644.

Shaul PW, Smart EJ, Robinson LJ, Guzman Z, Yuhanna IS et al. Acylation targets eNOS to plasmalemmal caveolae. J Biol Chem 1996; 271:6518-6522.

Shovlin CL, Angus G, Manning RA, Okoli GN, Govani S et al. Endothelial cell processing and alternately spliced transcripts of factor VIII: potential implications for coagulation cascade and pulmonary hypertension. PLoS One 2010; 5:e9154.

Siddiqui MR, Kamarova YA, Vogel SM, Gao X, Bonini MG et al. Caveolin-1-eNOS signaling promotes p190RhoGAP-A nitration and endothelial permeability. J Cell Biol 2011; 193:841-850. 
Simonneau G, Galie N, Rubin LJ, Langleben D, Seeger et al. Clinical classification of pulmonary hypertension. J Am Coll Cardiol 2004:43:5S-12S.

Sinha B, Köster D, Ruez R , Gonnord P, Bastiani M et al. Cells respond to mechanical stress by rapid disassembly of caveolae. Cell 2011; 144:402-413.

Smadja DM, Gaussem P, Mauge L, Lacroix R, Gandrille S et al. Comparison of endothelial biomarkers according to reversibility of pulmonary hypertension secondary to congenital heart disease. Ped Cardiol 2010; 31:657-662.

Song Y, Coleman L, Shi J, Beppu H, Sato K et al. Inflammation, endothelial injury and persistent pulmonary hypertension in heterozygous BMPR2 mutant mice. Am J Physiol 2008; 295:H677-H690.

Soon E, Holmes AM, Treacy CM, Doughty NJ, Southgate L et al. Elevated levels of inflammatory cytokines predict survival in idiopathic and familial pulmonary arterial hypertension. Circulation 2010; 122:920-927.

Spisni E, Griffoni C, Santi S, Riccio M, Marulli R et al. Colocalization of prostacyclin (PGI2) synthase-caveolin-1 in endothelial cells and new roles for PGI2 an angiogenesis. Expt Cell Res 2001; 266:31-43.

Starke RD, Ferraro F, Paschalaki KE, Dryden NH, McKinnon TA et al. Endothelial von Willebrand factor regulates angiogenesis. Blood 2011; 117:1071-1080.

Stenmark KR, Rabinovitch M. Emerging therapy for the treatment of pulmonary hypertension. Pediatr Crit Care Med 2010; 11:S85-S90.

Stitham J, Midgett C, Martin KA, Hwa J. Prostacyclin: an inflammatory paradox. Front Pharmacol 2011; 2:24

Taddei A, Giampietro C, Conti A, Orsengo F, Brevario F et al. Endothelial adherens junctions control tight junctions by VE-cadherin-mediated upregulation of claudin5. Nat Cell Biol 2008; 10:923-934.

Teichert-Kuliszewska K, Kutryk MJ, Kuliszewski MA, Karoubi G, Courtman DW et al. Bone morphogenetic protein receptor-2 signaling promotes pulmonary arterial endothelial cell survival. Implication for loss-of-function mutations in the pathogenesis of pulmonary hypertension. Circ Res 2006; 98:209-217.

Thibeault S, Rautureau Y, Oubaha M, Faubert D, Wilkes BC et al. S-nitrosylation of $\beta$ catenin by eNOS-derived NO promotes VEGF-induced endothelial cell permeability. Mol Cell 2010; 39:468-476.

Thomson JR, Machado RD, Pauciulo MW, Morgan NV, Humbert M et al, Sporadic primary pulmonary hypertension is associated with germline mutations of the gene encoding BMPR-II, a receptor member of the TGF-beta family. J Med Genet 2000; 37:741-745.

Thurston G, Rudge JS, Ioff E, Zhou H, Ross L et al Angiopoietin-1 protects the adult vasculature against plasma leakage. Nat Med 2000; 6:460-463.

Tuder RM, Groves B, Badesch DB, Voelkel NF. Exuberant endothelial cell growth and elements of inflammation are present in plexiform lesions of pulmonary hypertension. Am J Path 1994; 144:275-285.

van Buul JD, Kanters E, Hordjik PL. Endothelial signaling by Ig-like cell adhesion molecules. Arterioscl Thromb Vasc Biol 2007; 27:1870-1876. .

van Nieuw Amerongen GP, Beckers CM, Achekar ID, Zeeman S, Musters RJ et al. Involvement of Rho kinase in endothelial barrier maintenance. Arterioscler Thromb Vasc Biol 2007; 27:2332-2339. 
Vriens J, Owsiank G, Fisslthaler B Suzuki M, Janssens A et al. Modulation of $\mathrm{Ca}^{2}$ permeable cation channel TRPV4 by cytochrome P450 epoxygenases in vascular endothelium. Circ Res 2005; 97:908-915.

Wang H, Su Y. Collagen IV contributes to nitric oxide-induced angiogenesis of lung. Am J Physiol 2011; 300:C979-C988.

Yu H, Pardoll D, Jove R. STAT3 in cancer, inflammation and immunity: A leading role for STAT3. Nat Rev Cancer 2009; 9:798-809.

Yu PB, Deng DY, Beppu H, Hong CC, Lai C et al. Bone morphogenic protein (BMP) type II receptor is required for BMP-mediated growth arrest and differentiation in pulmonary artery smooth muscle cells. J Biol Chem 2008; 283:3877-3888.

Zhang XP, Hintze TH. cAMP signal transduction induces eNOS activation by promoting PKB phosphorylation. Am J Physiol 2006; 290:H2376-H2384.

Zhao YD, Courtman DW, Deng Y, Kugathasan L, Zhang Q et al. Rescue of monocrotalineinduced pulmonary arterial hypertension using bone marrow-derived endotheliallike progenitor cells. Efficacy of combined cell and eNOS gene therapy in established disease. Circ Res 2005; 96:442-450.

Zharikov SI, Block ER. Characterization of L-arginine uptake by plasma membrane vesicles isolated from cultured pulmonary arterial endothelial cells. Biochim biophys Acta 1369:173-183, 1998.

Ziche M, Morbidelli L, Choudhari R, Zhang HT, Donnini S et al. Nitric oxide synthase lies downstream from vascular endothelial growth factor-induced but not fibroblast growth factor-induced-angiogenesis. J Clin Invest 1997; 99:2625-2634. 


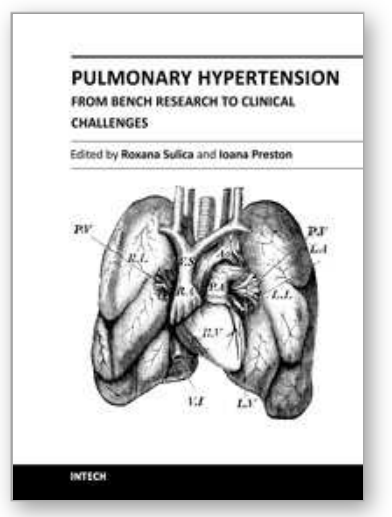

\section{Pulmonary Hypertension - From Bench Research to Clinical Challenges}

Edited by Dr. Roxana Sulica

ISBN 978-953-307-835-9

Hard cover, 326 pages

Publisher InTech

Published online 09, December, 2011

Published in print edition December, 2011

The textbook "Pulmonary Hypertension - From Bench Research to Clinical Challenges" addresses the following topics: structure and function of the normal pulmonary vasculature; disregulated cellular pathways seen in experimental and human pulmonary hypertension; clinical aspects of pulmonary hypertension in general; presentation of several specific forms of pulmonary hypertension, and management of pulmonary hypertension in special circumstances. The textbook is unique in that it combines pulmonary and cardiac physiology and pathophysiology with clinical aspects of the disease. First two sections are reserved for the basic knowledge and the recent discoveries related to structure and cellular function of the pulmonary vasculature. The chapters also describe disregulated pathways known to be affected in pulmonary hypertension. A special section deals with the effects of hypoxia on the pulmonary vasculature and the myocardium. Other three sections introduce the methods of evaluating pulmonary hypertension to the reader. The chapters present several forms of pulmonary hypertension which are particularly challenging in clinical practice (such as pulmonary arterial hypertension associated with systemic sclerosis), and lastly, they address special considerations regarding management of pulmonary hypertension in certain clinical scenarios such as pulmonary hypertension in the critically ill.

\section{How to reference}

In order to correctly reference this scholarly work, feel free to copy and paste the following:

Rajamma Mathew (2011). Pulmonary Hypertension: Endothelial Cell Function, Pulmonary Hypertension From Bench Research to Clinical Challenges, Dr. Roxana Sulica (Ed.), ISBN: 978-953-307-835-9, InTech, Available from: http://www.intechopen.com/books/pulmonary-hypertension-from-bench-research-to-clinicalchallenges/pulmonary-hypertension-endothelial-cell-function

\section{INTECH}

open science | open minds

\author{
InTech Europe \\ University Campus STeP Ri \\ Slavka Krautzeka 83/A \\ 51000 Rijeka, Croatia \\ Phone: +385 (51) 770447 \\ Fax: +385 (51) 686166 \\ www.intechopen.com
}

\author{
InTech China \\ Unit 405, Office Block, Hotel Equatorial Shanghai \\ No.65, Yan An Road (West), Shanghai, 200040, China \\ 中国上海市延安西路65号上海国际贵都大饭店办公楼 405 单元 \\ Phone: +86-21-62489820 \\ Fax: +86-21-62489821
}


(C) 2011 The Author(s). Licensee IntechOpen. This is an open access article distributed under the terms of the Creative Commons Attribution 3.0 License, which permits unrestricted use, distribution, and reproduction in any medium, provided the original work is properly cited. 